\title{
ENSAIOS TERAPÊUTICOS NO TRACOMA VISANDO A CAMPANHA DE TRATAMENTO EM MASSA *
}

\author{
Adolfo Pereira Arruda **, Raymundo N. A. Neves Netto***, José Rodrigues \\ da Silva $* * * *$ e Ivo Ferreira $* * * * *$
}

Uma nova sulfamita dc eliminaçāo prolongada, o Ro 4-4393, foi ensaiada na terapêutica do traccina, em 350 escolares de zona endêmica, em comparação ao aso tópico de antibióticos. Diverso ésquemas de administração foram adotados, desde $20 \mathrm{mg} / \mathrm{kg}$ ate $50 \mathrm{mg} / \mathrm{kg}$, a intervalos semanais, quinzenais, mensais e em dose única.

Os resultados obtidos com a maioria dos esquemas foram equiparáveis àqueles proporcionados pelo uso local de antibióticos. O tempo de contrôle é ainda insuficiente para conclusões definitivas, e sugere-se o estudo de novos esquemas posclógicos com c Ro 4-4393.

\section{INTRODUÇÃO}

Com o advento dos bacteriostáticos e dos antibióticos, novos horizontes se abriram na luta contra o tracoma. As sulfonamidas, empregadas a partir de 1938, modificaram de maneira impressionante o prognóstico da doença. A experiência norte-americana em populaçäo escolar demonstrou notável redução da incidência do tracoma, após instituição do tratamento por sulfas (Forster e $\mathbf{M c}$ Gibony, 4). O emprêgo em terapêutica de antibióticos de largo espectro, especialmente as tetraciclinas, veio acrescentar novas esperanças ao tratamento do tracoma, pois seu uso tópico parecia ser mais eficaz e melhor tolerado que a terapêutica sulfamídica (10). Bietti e Pannarale (2) obtiveram resultados favoráveis com a penicilina G Benzatina em doses de 2.000 e 2.500 u.p/ $\mathrm{kg}$. de pêso corporal, em inje ções quinzenais, num total de 5 a 7 aplicações. Conseguiram o desaparecimento das granulações conjuntivais em $67 \%$ dos casos, bem como a diminuição considerável em $18 \%$.

Kamiya e colaboradores (7) observaram 70,83\% de cura clínica em casos inci pientes, com cloromicetina. Moutinho e colaboradores (9) utilizaram a aureomicina em pomada oftálmica a $0,5 \%$ e $1,0 \%$ com resultados bem apreciáveis.

A terramicina mostrou-se altamente satisfatória na terapêutica do rracoma, conforme experiências de Kamiya e colaboradores (7), cujo percentual de cura atingiu a cifra de $60,71 \%$.

Não obstante o êxito conseguido com os antibióticos, principalmente cloranfenicol, terramicina e aureomicina, tornaram-se cada vez menos lisonjeiras as possibilidades do emprêgo como medicação sistemática, em campanhas de tratamento

Trabalho apresentado no VI Congresso Pan-Americano Interim de Oftalmologia. Rin do Janeiro, 16 a 21 de agôsto de 1965.

* Médics do D.N.E.Ru., Recife, Pernambuco.

** Médico do D.N:E.Ru., Belém, Pará.

* \# Diretoy do I.N.E.Ru., Rio de Janejro, GB, professor Catedrático da Clínica de Doenças Tropicais e Infectuosas da Fac. Med. da U.F.R.J. e da Fac. Ciências Méd. da U.E.G.

Médico-chefe do Depto. de Pesquisas Clínicas de Produtos Roche Químicos c Farmacêtutios

S. A., Rio de Janeiro. 
em massa, à medida que foram sendo melhor estudados seus efeitos colaterais. São bem conhecidos os perigos que oferecem os antibióticos de largo espectro, quando usados a longo praz̃o, na ausência de contrôle laboratorial.

Atualmente os antibióticos têm a preferência como tratamento tópico, em suspensão ou pomada oftálmica, conforme recomendaçōes do grupo de peritos em tracoma da O.M.S.

As novas sulfas de eliminação lenta vieram novamente modificar o panorama terapêutico do tracoma, pois permitem a adoção de esquemas posológicos práticos, com administração a intervalos mais longos, o que é bastante apropriado para campanhas de tratamento em massa.

O uso de suifas vem já sendo adotado no D. N. E. Ru., em trabalhos de campo no tracoma, há bastante tempo Foram já usadas as sulfadiazina e as associações de 3 sulfas, em doses diárias de 0,04 a $0,05 \mathrm{~g} / \mathrm{kg}$ de pêso corporal, por períodos de 20 dias, repetidos após 10 dias de descanso (3)

Tais esquemas são contudo impraticáveis em grandes grupos de população, sobretudo na zona rural. Mais recentemente (1962 e 1963), o D.N.E.Ru. empregou em Pernambuco duas das chamadas sulfas de eliminação lenta: sulfametoxipiridazina e sulfametoxipirimidina. Associadas à terapêutica local com pomada de tetraciclina, proporcionaram resultadcs bastante sátisfatórios, confirmando portanto o trabalho pioneiro de Bietc1 e colaboradores (1) com a primeira, em administração a intervalos semanais e quinzenais.

O Ro 4-4393, quimioterápico da série da sulfadiazina, recentemente sintetizado por F. Hoffmann-La Roche \& Cie., parece apresentar vantagens especiais para a terapêutica em massa do tracoma, pois é caracterizado por uma eliminação extremamente lenta, permanecendo no organismo em níveis terapêuticos por tempo bastante superior ao das outras sulfas modernas; seu período de meiaeliminação é de 100 a 200 horas, portanto 3 a 6 vêzes mais prolongado que o das outras sulfas "retard" até então ensaiadas. Por outro lado, sua absorção pelo organismo é rápida, alcançando-se concentrações teranêuticas nc plasma 2 a 4 horas após a administração de dose oral adequada.

O Ro 4-4393 tem sido usado no tratamento de diversás infecçōes sensivers, apresentando especial interêsse os ensaios conduzidos na terapêtica da lepra, da blastomicose sul-americana e do tracoma; os estudos em lepra e blastomicose demonstraram a toxicidade extremamente reduzida do Ro 4-4393, mesmo quando administrado $\mathrm{em}$ ćcse elevada por longos períodos. Dentre os ensaios no tracoma, particularmente importantes para nós, destacam-se os trabalhos de Tittarelli (11), Gandolfi (5), Milano (8).

Tittarelli (11) tratou 80 escolares portadores de TrII, administrando o quimioterápico em doses de $20 \mathrm{mg} / \mathrm{kg}$, uma vez por semana, até a cura clínica. Aos $\mathbf{8 0}$ dias de tratamento, cêrca de $50 \%$ dos pacientes estavam curados e, ao final de 4 meses, todos os casos foram considerados curados, com desaparecimento completo das papilas e folículos.

Gandolfi (5) observou 160, casos, dividindo-os em dois grupos: um tratado exclusivamente por doses semanais de Ro 4-4393, o segundo pela sulfa e aplicação local de antibiótico. $O$ tratamento foi mantido por 3 meses e 2 meses após o seu término os resultados mostraram $82 \%$ de cura no primeiro grupo e $86 \%$ no segundo.

Milano (8) administrou o Ro 4-4393 a 48 escolares com tracoma no segundo estádio; 23 casos foram tratados com $20 \mathrm{mg}$ $\mathrm{kg}$ de pêso cada dez dias e os outros 25 pacientes receberam a mesma dose a intervalos de doze dias, durante um periodo de três meses. Três meses após o início do tratamento, 17 pacientes do primeiro grupo e 18 do segundo estavam curados. Ao final do sexto mês, as percentagens de cura foram de $82,6 \%$ e $84 \%$, respectivamente para os dois grupos.

Em nenhum dos ensaios acima mencionados foi observado qualquer efeito tóxico do novo medicamento ou reação de hipersensibilidade.

Esses resultados fizeram com que o Instituto Nacional de Endemias Rurais programasse, em colaboração com c D.N.E.Ru., através de suas Circunscrições Regionais do Pará, Ceará e Pernambuco, um ensaio de campo com o Ro 4-4393 (6). Tal ensaio teria como finalida- 
de principal a escolha de um esquema terapêutico simples, com doses reduzidas ds quimioterápico, esquema aplicável às precárias condições sanitárias das zonas endêmicas de tracoma do nosso país.

\section{MATERIAL E METODOS}

A pesquisa foi levada a efeito em populações escolares, não só pela maior facilidade de contrôle, como também por constituir amostra bem representativa da população. A escolha de escolares é particularmente adequada ao estudo do tracoma, doença de foco familiar por excelência, e que incide predominantemente nos grupos etários mais jovens, onde se encontra largo percentual de formas evolutivas ( $T r$ I, II e. III).

Os ensaios foram realizados em 350 crianças, selecionadas na cidade de Belém (Pará) e nas localidades de Paratibe, Paulista, São Lourenço da Mata, Usiná Tiúma e Taquaritinga do Norte (zona rural de Pernambuco). A seleção dos pacientes foi feita de modo a obter mostragem homogênea quanto ao estádio do tracoma, idade, condições econômica e social, focos familiares, infecções concomitantes, etc. Os doentes foram divididos em 8 grupos, 6 dos quais receberam 0 Ro 4-4393 segundo diferentes equema'; dois permanecendo como grupos-contrôle, tratados com aplicações locais de pomada de antibiótico. O Ro 4-4393 foi adm:nistrado por via oral, exceção feita a um dos grupos.

Se bem que o Ro 4-4393 não pareça apresentar os inconvenientes de toxicidade dos primeiros sulfamídicos, evitou-se a sua administração a pessoas com comprometimento declarado das funções renal ou hepática, assim como a parientes hipersensíveis a sulfas.

A posologia e esquemas de administração adotado:s estão registrados no Quadro I.

O contrôle de cura, feito sempre que possível a intervaios mensais, baseou-se em exame com lâmpada de fenda portátil (Bausch Lomb) ov: lupa de Berger, material semiotécnico disponível nos serviços; foi adotado em linhas gerais o critério de cura preconizado pela comissão de peritos de tracoma da Organização Mundial de Saúde.

Os casos foram considerados como:

a) Inalterados - quando não havia qualquer sinal de melhora, ou quando tais sinais eram muito incipientes;

b) Pouco me!horados - ausência de modificações quanto à forma, e regressão quanto à intensidade das lesões objetivas, tais como folículos e panos;

c) Muito melhorados - evolução da forma inicial ( $\operatorname{Tr}$ I e II) para a fase de cicatrização, evidenciando a proximidade da cura do processo;

d) Parcialmente curados - doentes que, apesar de terem atingido o grau IV, apresentam ainda aiguns elementos objetivos, tais como papilas, infiltração corneana, etc.;

e) Curados - cicatrização total ou regressão total das lesões objetivas, sem reliquat cicatricial.

\section{RESULTADOS}

Os resultados acham-se computados nos Quadros II a X.

O Quadro II mostra os resultados do tratamento no grupo $A$, composto de 53 pacientes aos quais se administrou o Ro 4-4393 por via oral, em doses únicas semanais de $20 \mathrm{mg} / \mathrm{kg}$ te pêso corpora!, durante 4 semanas (total de 4 administracões). Metade coos casos fôra classificada com $\mathrm{Tr}$ II e metade como $\mathrm{Tr}$ III, ances do tratamento; um mês após o término da terapêutica, 50 casos foram examinados e constatou-se que 4 paciertes apresentavain-se bastante melhorados. Resultado semelhante foi obtido no contrôle de 2 meses. No quinto mês após o tratamento, 21 casos $(51,4 \%)$ foram considerados como curados, e os restantes 20 pacientes controlados $(48,6 \%)$ achavarn -se nitidamente melhorados. 
Rev. Soc. Bras. Med. Tro ${ }_{j}$

Vol. I - N: 4

Quadro I

RO 4-4393 THO TRACOMA : ESQUEMAS TERAPEUTICOS

(via oral)

\begin{tabular}{|c|c|c|c|c|}
\hline GRUPO & $\begin{array}{c}\text { DOSES } \\
\text { (MG/KG) }\end{array}$ & $\begin{array}{l}\text { INTERVALO } \\
\text { ENTRE AS DOSES }\end{array}$ & $\begin{array}{l}\text { DURAÇAO DO } \\
\text { TRATAMENTO }\end{array}$ & $\begin{array}{l}\text { NUMERO DE CASOS } \\
\text { CONTHOLADOS }\end{array}$ \\
\hline A & 20 & 7 dias & $4 \times 7$ dias & 41 \\
\hline B & 25 & 7 dias & $4 \times 7$ dias & 51 \\
\hline$c *$ & 20 & 7 dias & $4 \times 7$ dias & 37 \\
\hline D & 25 & 15 d1as & $4 \times 15$ dias & 45 \\
\hline$E$ & 20 & 30 dias & $3 \times 30$ diss & 38 \\
\hline$F$ & 50 & - & dose unica & 50 \\
\hline c & pomada & oxitetraciclina & $* *$ & 33 \\
\hline H & pomada & clortetraciclina & $* *$ & 55 \\
\hline
\end{tabular}

- Via intramuscular

350 casos

* 2 vêzes ao dia, por 45 a 60 dias

No Quadro III estão referidos os résultados do tratamento de 51 doentes (Grupo B), tratados pelo Ro 4-4393, mediante uso oral de doses únicas semanais de $25 \mathrm{mg} / \mathrm{kg}$ de pêso corporal, durante 4 semanas. No tim do tratamento, apenas $5,9 \%$ de pacientes apresentaram-se muito melhorados, sem qualquer caso de cura a registrar. Aos 30 dias após a conclusão do tratamento, vamos encontrar $27,5 \%$ de doentes muito melhorados e $7,8 \%$ de pacientes parciaimente curados.

Após 60 dias, tivemos um aumento dos casos parcialmente curados para $23,5 \%$, enquanto que foram registrados os primeiros resultados de cura clínica, com um percentual de 2,0 . Com o prosseguimento das inspeções subseqüentes fomos registrar acs 90 dias após a conclusão do tratamento, cêrca de $45,1 \%$ de cura, restando ainda $15,7 \%$ de pacientes em adiantado estado de cicatrização.

O Quadro IV refere os resultados obtidos no Grupo C, tratado por via intramuscular com doses de $20 \mathrm{mg} / \mathrm{kg}$ de pêso por semana, curante 4 semanas. Os pacientes apresentavam antes do tratamento tracoma grau II (39 casos) ou grau III (15 casos). Um mês após o fim da terapêutica 2 casos estavam jà consideràvelmente melhorados; o contrôle de 2 meses mostrou 12 casos melhorados e 1 curado, e a avaliação no quinto mês após o tratamento classificou 15 casos como curados $(40,5 \%)$ e os restantes 22 $(59,5 \%)$ bastante melhorados.

O Quadro V registra o resultado obtido em 45 tracomátosos tratados com o Ro 4-4393, em doses de $25 \mathrm{mg} / \mathrm{kg}$ de pêso ccrporal cada 15 dias, duiante 4 quinzenas (Grupo D). No fim do $1^{\circ}$ mês de tratamento, tivemos a registrar ape. nas $11,1 \%$ de doentes pouco melhorados, enquanto que $88,9 \%$ conservaram-se sem modificação. No fim do tratamento já se verificaram $17,8 \%$ de tracomatosos bem melhorados. Aos 30 dias mais, surgiram $6,7 \%$ de casos parcialmente curados e $31,1 \%$ de muito melhorados. No final do período de observação, ou seja, 60 dias após a conclusão do tratamento, tivemos a registrar $31,1 \%$ de doentes curados clìnicamente e mais $28,9 \%$ de formas muito melhoradas.

Os resultados obtidos no Grupo E estão expcstos no Quadro VI. Esses pacientes receberam 3 doses mensais de $20 \mathrm{mg} / \mathrm{kg}$ do Ro 4-4393, por via oral. Inicialmente portadores de $\operatorname{Tr}$ II (39 casos) e Tr III (14 casos), os pacientes já 


\section{Quadro II}

Tratamento do tracoma com o Ro 4-4393: Grupo A

Pacientes tratados com $20 \mathrm{mg} / \mathrm{kg}$ em doses semanais durante 4 semanas por via oral

\begin{tabular}{|c|c|c|c|c|c|c|c|c|}
\hline \multirow[t]{2}{*}{ Aspectos CIfnicos } & \multicolumn{4}{|c|}{ 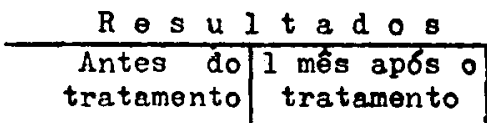 } & \multicolumn{2}{|c|}{ 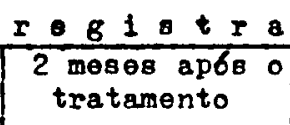 } & \multicolumn{2}{|c|}{ 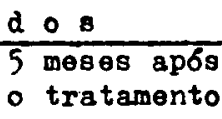 } \\
\hline & Casos & $\%$ & Casos & $\%$ & Casos & $\not$ & Casos & $q$ \\
\hline Tr II & 25 & 47,2 & 1 & 2,0 & 0 & - & 0 & - \\
\hline $\operatorname{Tr} I I-I I I$ & 0 & - & 29 & 58,0 & 27 & 60,0 & 0 & - \\
\hline Tr III & 28 & 52,8 & 16 & 32,0 & 16 & 35,6 & 0 & - \\
\hline Ir III-IV & 0 & - & 4 & 8.0 & 2 & 4,4 & 20 & 48,6 \\
\hline Tr IV & 0 & - & 0 & - & 0 & - & 21 & 51,4 \\
\hline Total & 53 & $100 \%$ & 50 & $100 \%$ & 45 & $100 \%$ & 42 & $100 \%$ \\
\hline
\end{tabular}

Quadro III

Tratamento do tracoma com o Ro 4-4393: Grupo B

Paclentes tratados com $25 \mathrm{mg} / \mathrm{kg}$ em doses semanais, durante 4 semanas,

por via oral

\begin{tabular}{|c|c|c|c|c|c|c|c|c|}
\hline \multirow{3}{*}{$\begin{array}{c}\text { Aspectos clintcos } \\
\text { dos } \\
\text { Doentes Examinados }\end{array}$} & \multicolumn{8}{|c|}{$R \bullet a u t a d \circ s$} \\
\hline & \multicolumn{2}{|c|}{$\begin{array}{l}\text { No fim do } \\
\text { tratamento }\end{array}$} & \multicolumn{2}{|c|}{$\begin{array}{c}1 \text { mess ap } 6 s 0^{\circ} \\
\text { tratamento }\end{array}$} & \multicolumn{2}{|c|}{$\begin{array}{l}2 \text { meses ap6s } \\
0 \text { tratamento }\end{array}$} & \multicolumn{2}{|c|}{$\begin{array}{l}3 \text { meses apds } \\
\text { e tratamento }\end{array}$} \\
\hline & No & $\%$ & Ne & $\%$ & No & $\%$ & Ne & $\%$ \\
\hline Sem modificagăo & 29 & 56,9 & 13 & 25,5 & 7 & 13,7 & 5 & 9,8 \\
\hline Pouco melhorados & 19 & 37,2 & 20 & 39,2 & 21 & 41,2 & 15 & 29,4 \\
\hline Mus to melhorados & 3 & 5,9 & 14 & 27,5 & 10 & 19,6 & 8 & 15,7 \\
\hline $\begin{array}{l}\text { Parcialmente curados } \\
\text { Curados }\end{array}$ & 0 & - & 4 & 7,8 & 12 & 23,5 & 0 & - \\
\hline Total & 51 & 100,0 & 51 & 100,0 & 51 & 100,0 & 51 & 100,0 \\
\hline
\end{tabular}




\section{Quadro IV}

Iratamento do tracoma com o Ro 4-4393, Cmupo $C$

Pacientes tratados $\operatorname{com} 20 \mathrm{mg} / \mathrm{kg}$ em doses semanals durante 4 somanas.

por vio intramuscular

\begin{tabular}{|c|c|c|c|c|c|c|c|c|}
\hline \multirow{3}{*}{ Aspectos elfnicos } & \multicolumn{8}{|c|}{ Resultados IOBIBtrados } \\
\hline & \multicolumn{2}{|c|}{$\begin{array}{l}\text { Antos do } \\
\text { tratimento }\end{array}$} & \multicolumn{2}{|c|}{$\begin{array}{l}2 \text { mos ap6s o } \\
\text { tretnmento }\end{array}$} & \multicolumn{2}{|c|}{$\begin{array}{c}2 \text { meses apbs } \\
0 \text { tratamento }\end{array}$} & \multicolumn{2}{|c|}{$\begin{array}{l}5 \text { mogos ap } 6 s \\
0 \text { tratamento }\end{array}$} \\
\hline & Casos & 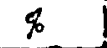 & Casos & $\not$ & Casosi & $\not$ & Casos & $\%$ \\
\hline Tr II & 39 & 72,2 & 4 & 8,3 & 1 & 3,0 & $\mathbf{0}$ & - \\
\hline Tr II-III & 0 & - & 37 & 77,0 & 19 & 57.5 & 0 & - \\
\hline Tr III & 15 & 27.8 & 5 & 20,6 & 12 & 36,5 & 0 & - \\
\hline Tr III-IV & 0 & - & 2 & 4,1 & 0 & - & 22 & 59.5 \\
\hline Tr IV & ค & - & 0 & - & 1 & 3,0 & 15 & 40.5 \\
\hline Total & 54 & $100 \%$ & 48 & $100 \%$ & 33 & $100 \%$ & 37 & $100 \%$ \\
\hline
\end{tabular}

\section{Quadro V}

Tratamento do tracoma com o Ro 4-4393: Grupo D

Paosentes tratados com $25 \mathrm{mg} / \mathrm{kg}$ a intervalos quinzenais, durante 4 quinzenas por via oral

\begin{tabular}{|c|c|c|c|c|c|c|c|c|}
\hline \multirow{3}{*}{$\begin{array}{l}\text { Aspeotos clínicos } \\
\text { dos } \\
\text { Doentes examinados }\end{array}$} & \multicolumn{8}{|c|}{ 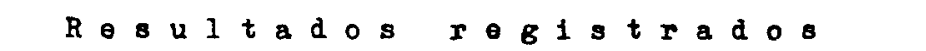 } \\
\hline & \multicolumn{2}{|c|}{$\begin{array}{l}19 \text { moss de } \\
\text { tratamen to }\end{array}$} & \multicolumn{2}{|c|}{$\begin{array}{l}\text { Fim do } \\
\text { tratamento }\end{array}$} & \multicolumn{2}{|c|}{$\begin{array}{l}1 \text { mes apos } \\
0 \text { tratamento }\end{array}$} & \multicolumn{2}{|c|}{$\begin{array}{l}2 \text { moses apos } \\
0 \text { tratamento }\end{array}$} \\
\hline & Ne & $\%$ & $\mathrm{Ne}$ & $\%$ & $\mathrm{~N}^{2}$ & $\%$ & $\mathrm{Ne}$ & $\not 0$ \\
\hline Sem modificagão & 40 & 88,9 & 25 & 55,5 & 13 & 28,9 & 4 & 8,9 \\
\hline Pouco melhorados & 5 & 11,1 & 12 & 26.7 & 15 & 33,3 & 14 & 31,1 \\
\hline Muito melhorados & 0 & - & 8 & 17,8 & 14 & 31,1 & 13 & 28,9 \\
\hline Parcialmente curados & 0 & - & 0 & - & 3 & 6,7 & 0 & - \\
\hline Curados & 0 & - & 0 & - & 0 & - & 14 & 31,1 \\
\hline Total & 45 & 100,0 & 45 & 100,0 & 45 & 100,0 & 45 & 100,0 \\
\hline
\end{tabular}




\section{Quadro VI}

Tratamento do tracoma com o Ro 4-4393 : Grupo E

Pacientes tratados com $20 \mathrm{mg} / \mathrm{kg}$ om doses mensais durante 3 mesos, por via oral

\begin{tabular}{|c|c|c|c|c|c|c|c|c|}
\hline \multirow{3}{*}{ Aspectos elsnicos } & \multicolumn{8}{|c|}{ Resultados reglatrados } \\
\hline & \multicolumn{2}{|c|}{$\begin{array}{l}\text { Antes do } \\
\text { tratamento }\end{array}$} & \multicolumn{2}{|c|}{$\begin{array}{l}1 \text { mess após o } \\
\text { tratamento }\end{array}$} & \multicolumn{2}{|c|}{$\mid \begin{array}{ll}2 & \text { moses ap } \\
0 & \text { tratamento }\end{array}$} & \multicolumn{2}{|c|}{$\begin{array}{l}5 \text { meses ap6s } \\
\text { o tratadisnto }\end{array}$} \\
\hline & Casos & $\%$ & Casos & 8 & Casos & $\phi$ & Casos & $\%$ \\
\hline Tr II & 39 & 73,6 & 2 & 4,2 & 1 & 2,9 & 0 & - \\
\hline $\operatorname{Tr} I I-I I I$ & 0 & -1 & 14 & 29,1 & 16 & 38,2 & 0 & - \\
\hline $\operatorname{Tr}$ III & 14 & 26,4 & 30 & 62,5 & 23 & 56,0 & 0 & - \\
\hline Tr III-IV & 0 & - & 2 & 4,2 & 0 & - & 20 & 52,7 \\
\hline Is IV & 0 & - & 0 & - & 1 & 2,9 & 18 & 47,3 \\
\hline Total & 53 & $100 \%$ & 48 & $100 \%$ & 41 & $100 \%$ & 38 & $100 \%$ \\
\hline
\end{tabular}

Quadro VII

Tratamento do tracoma com o Ro 4-4393: Grupo F Pacientes tratados com $50 \mathrm{mg} / \mathrm{kg}$, em dose ínica, por via oral

\begin{tabular}{|c|c|c|c|c|c|c|c|c|}
\hline \multirow[b]{4}{*}{ Sem modificaçăo } & \multicolumn{8}{|c|}{$R \in s u I t a d o$ a $x$ e istrados } \\
\hline & \multicolumn{2}{|c|}{1 mês após a } & \multicolumn{2}{|c|}{$\begin{array}{l}2 \text { meses apos } \\
\text { a medicsğăo }\end{array}$} & \multicolumn{2}{|c|}{$\begin{array}{l}3 \text { meser apbs } \\
\text { a medioagăo }\end{array}$} & \multicolumn{2}{|c|}{$\begin{array}{l}4 \text { meses ap } \delta \\
\text { a medicação }\end{array}$} \\
\hline & No & $\%$ & Ne & $\%$ & $\mathrm{~N}^{2}$ & $\%$ & No & $\not 0$ \\
\hline & 36 & 72,0 & 24 & 48,0 & 10 & 20,0 & 8 & 16,0 \\
\hline Fouco melhorados & 11 & 22,0 & 19 & 38,0 & 20 & 40,0 & 20 & 40,0 \\
\hline Mui to melhorados & 2 & 4,0 & 5 & 10,0 & 12 & 24,0 & 13 & 26,0 \\
\hline Farcialmente curados & 0 & - & 0 & - & 3 & 6,0 & 0 & - \\
\hline Curados & 0 & - & 1 & 2,0 & 5 & 10,0 & 9 & 18,0 \\
\hline Total & $49 *$ & 98,0 & $49 *$ & 98,0 & 50 & 100,0 & 50 & 100,0 \\
\hline
\end{tabular}

* Faltou 1 doento ao exame. 


\section{Quadro VIII}

Tratamento do tracoma com oxitetraciclina: Grupo G

Paciontes tratados com pomada oftálmica comercial, duas aplicegóos locais diárias durante 45 dias

\begin{tabular}{|c|c|c|c|c|c|c|c|c|}
\hline \multirow{3}{*}{$\begin{array}{c}\text { Aspootos elfnicos } \\
-\end{array}$} & \multicolumn{8}{|c|}{$R \circ B$ u I t ados rogistrados } \\
\hline & \multicolumn{2}{|c|}{$\begin{array}{r}\text { Antes do } \\
\text { tratamento }\end{array}$} & \multicolumn{2}{|c|}{$\begin{array}{c}1 \text { mes aposs o } \\
\text { tratamento }\end{array}$} & \multicolumn{2}{|c|}{$\begin{array}{l}2 \text { mosos ap } \delta s \\
0 \text { tratamento }\end{array}$} & \multicolumn{2}{|c|}{$\begin{array}{l}5 \text { meses após } \\
0 \text { tratamento } \\
\end{array}$} \\
\hline & Casos & $\%$ & Cason & $\%$ & Casos & $\&$ & Casos & 8 \\
\hline Tr II & 26 & 49,0 & 0 & - & 0 & - & 0 & - \\
\hline Tr II-III & 0 & - & 12 & 24,0 & 3 & 7,3 & 0 & - \\
\hline Tr III & 27 & 51,0 & 33 & 66,0 & 31 & 75,6 & 0 & - \\
\hline Tr III-IV & 0 & - & 5 & 10,0 & 2 & 4,9 & 16 & 48,5 \\
\hline $\operatorname{Tr} I V$ & 0 & - & 0 & - & 5 & 12,2 & 17 & 51,5 \\
\hline Total & 53 & $100 \%$ & 50 & $100 \%$ & 41 & $100 \%$ & 33 & $100 \%$ \\
\hline
\end{tabular}

Quadro IX

Tratamonto do tracoma com clortetraciclina : Grupo B Paclentos tratados com pomada oftélmica comercisl, duas aplieacōes locais diárias durante 60 dias

\begin{tabular}{|c|c|c|c|c|c|c|c|c|}
\hline \multirow{3}{*}{$\begin{array}{l}\text { Aspoctos clinicos dos } \\
\text { doentes examinados }\end{array}$} & \multicolumn{8}{|c|}{ Resultados R०B 1 strados } \\
\hline & \multicolumn{2}{|c|}{$\begin{array}{l}10 \text { mos do } \\
\text { tratamento }\end{array}$} & \multicolumn{2}{|c|}{$\begin{array}{l}28 \text { mes de } \\
\text { tratamento }\end{array}$} & \multicolumn{2}{|c|}{$\begin{array}{c}10 \text { mes apds } \\
\text { tratamento }\end{array}$} & \multicolumn{2}{|c|}{$\begin{array}{c}2 \text { meses apos } 0 \\
\text { tratamento }\end{array}$} \\
\hline & No & $\$$ & no & $\%$ & $N^{2}$ & $\%$ & no & $\%$ \\
\hline Sem modificagăo & 51 & 92,7 & 21 & 38,2 & 5 & 9,1 & 4 & 7,3 \\
\hline Pouco melhorados & 3 & 5,5 & 23 & 41,8 & 22 & 40,0 & 23 & 41,8 \\
\hline Mus to molhorados & 1 & 1,6 & 6 & 10,9 & 9 & 16,4 & 9 & 16,4 \\
\hline $\begin{array}{l}\text { Parolelmento curados } \\
\text { Ourados }\end{array}$ & $\begin{array}{l}0 \\
0\end{array}$ & - & 5 & 9.1 & 11 & 20,0 & 0 & - \\
\hline Total & 55 & 100,0 & 55 & 100,0 & 55 & 100,0 & 55 & 100,0 \\
\hline
\end{tabular}


Quadro $x$

Tratamento do tracoma com o Ro 4-4393:

Rosultados gerais do último controlo

\begin{tabular}{|c|c|c|c|c|}
\hline Grupo & Seguimento & Inal terados & $\begin{array}{l}u l+a d 0 \\
\text { Melhorados }\end{array}$ & $\begin{array}{c}e m \\
\text { Curados }\end{array}$ \\
\hline A $(20 \mathrm{mg} / \mathrm{kg} /$ semana $)$ & 5 meses & - & 48.5 & 51,5 \\
\hline$B\left(25 a_{B} / k_{B} /\right.$ semana $)$ & 3 neses & 39.2 & 15,7 & 45,1 \\
\hline$C(20 \mathrm{mg} / \mathrm{kg} / \mathrm{semana})$ & 5 mesos & - & 59,5 & 40,5 \\
\hline $\mathrm{D}(25 \mathrm{mg} / \mathrm{kg} /$ quinzena $)$ & 2 moses & 10,0 & 28,9 & 31,1 \\
\hline$-E(20 \mathrm{mg} / \mathrm{kg} / \mathrm{mg})$ & $5 \operatorname{meses}$ & - & 52,7 & 47,3 \\
\hline$F(50 \mathrm{mg} / \mathrm{kg}, 1 \operatorname{dos} \theta)$ & 4 meses & 56,0 & 26,0 & 18,0 \\
\hline$G$ (Oxitetraoiclina) & 5 meses & - & 48,5 & 51,5 \\
\hline B (clortetraciclina) & $2 \operatorname{mes} \theta$ & 49,2 & 16,4 & 34,5 \\
\hline
\end{tabular}

- Onico grupo tratado por via parenteral (I.M.)

apresentavam melhora 1 mês após o tratamento, onde se observaram 2 casos bastante melhorados. No contrôle do segundo mês, havia 1 caso curado e, 5 meses após o fím da terapêutica, 18 casos $(47,3 \%)$ estavam curados e $20(52,7 \%)$ melhorados.

Quadro VII: Pacientes tratados com Ro 4-4393, com uma única dose de $50 \mathrm{mg} / \mathrm{kg}$ de pêso corporal (Grupo F). Nada houve a registrar de cura clínica 30 dias após a medicação. Aos 60 dias após a medicação tivemos $2,0 \%$ de cura clínica e 10,0\% de pacientes muito melhorados. Três meses após, encontramıs $\mathbf{1 0 , 0} \%$ de cura e $24,0 \%$ de casos muito melhorados, além de $6,0 \%$ de formas parcialmente curadas. No final da observação, ou seja 4 meses após, tivemos $18,0 \%$ de pacientes clìnicamente curados.

Os Quadros VIII e IX contêm us resultados obtidos nos Grupos G e H, tra* tados por pomada oftálmica de oxitetraciclina e clortetraciclina, respectivamente, para efeito de comparação com a terapêutica pelo Ro 4-4393. A pomada de oxitetraciclina foi administrada durante 45 dias, em duas aplicações locais diárias (Grupo $\mathbf{G}$ ), e proporcionou os seguintes resultados: 5 casos bastante melhorados 1 mês após o tratamento; 5 casos curadns e 2 melhorados no segundo contrôle (2 meses); 17 casos curados (51,5\%) e 16 melhorados $(48,5 \%)$ ao fim de 5 meses após o tratamento. A pomada de clortetraciclina foi usada no Grupo $\mathbf{H}$, em duas aplicações diárias durante 2 meses. Com 1 mês de tratamento tivemos apenas $1,8 \%$ de casos muito melhorados. No $2^{\circ}$ mês de tratamento passamos a ter 9,1\% de casos parcialmente curados. Trinta dias após a conclusão do tratamento registramos $14,5 \%$ de pacientes curados e mais $20,0 \%$ parcialmente curados. No final da observação, ou seja ? meses após a conclusão do tratamento, tivemos a presença de $34,5 \%$ de doentes curados e 18,0\% bem melhorados.

Finalmente, no Quadro X estão reunidos em conjunto os resultados de todos os grupos tratados, tanto pelo Ro 4-4393 nos diversos esquemas como pelas pomadas de antibióticos, de acôrdo com o último contrôle efetuado. Podemos verificar que os índices de cura para o $\mathbf{R o}$ 4-4393 são pelo menos semelhantes àquêles proporcionados pelo tratamento local com oxitetraciclina e clortetraciclina.

No que se refere a efeitos secundários, não foi observado um só caso de reação imputável ao nôvo quimioterápico, mesmo 
naqueles pacientes que receberam dose de $50 \mathrm{mg} / \mathrm{kg}$ de pêso.

\section{DISCUSSÃO E CONCLUSÕES}

O uso das sulfas de ação prolongada parece oferecer vantagem sôbre - emprêgo de antibióticos sistêmicos ou locais. Sôbre os primeiros, tem a vantagem da menor toxicidade e menor interferência com a flora normal do organismo; quanto às pomadas e suspensões oculares de antibióticos, seu uso na prática nem sempre é observado com rigor, especialmente no que se refere às campanhas de tratamento em massa do tracoma.

Nossa experimentação com o Ro 4-4393, de ação "ultraprolongada", veio comprovar os trabalhos de outros autores com o mesmo quimioterápico, demonstrando ser o produto um recurso eficaz. de toxicidade pràticamente nula, e bastante prático para trabalho de campo em zonas de baixo índice de educação sanitária.

Os índices de cura que obtivemos, tanto para o Ro 4-4393 como para o tratamento padrão com pomada de antibiótico, foram inferiores aos relatados na literatura. Há que considerar, contudo, os seguintes fatos: a) o tempo de contrôle é ainda insuficiente para avaliação final pois, no consenso geral dos estudiosos, os melhores índices são observados a parti: do sexto mês após o término do tratamento; b) no caso do Ro 4-4393, fizemos uso de posologia e tempo de administração inferiores aos adotados por outros autores. Novos esquemas estão já programados pelo I.N.E.Ru., com doses mais elevadas e tratamento mais prolongado; c) quanto aos grupos tratados por antibióticos, é válida também a primeira consideração feita acima. Além disso, é possível que nossas recomendaçōes para aplicação da pomada duas vêzes ao dia, por período ininterrupto de. 45 a 60 dias, não tenham sido seguidas à risca por todos os pacientes; consideramos êsse fath como deficiência própria ao método terapêutico, no que se refere ao tratamento em massa, sendo portanto mais um argumento em favor do uso sistêmico de sulfas modernas; d) há fatôres imponderáveis que podem influir nos resultados da tera- pêutica do tracoma: raça do vírus, estado imunitário, reatividade constitucional e outros fatôres ambientais.

Convém salientar que o uso de doses, baixas de Ro 4-4393, e períodos relativamente curtos de tratamento, adotados na maioria dos nossos esquemas (em contraposição aos trabalhos de outros pesquisadores) foi baseado no fato de ser o Ro 4-4393 a sulfamida de eliminação mais prolongada que conhecemos. Portanto, se outras sulfamidas, cuja administração é habitualmente feita a intervalos de 24 horas e em doses duas vêzes superiores às do Ro 4-4393, foram eficazes no tracoma em administração semanal, justifica-se plenamente o uso de doses reduzidas do nôvo quimioterápico, a intervalos superiores a uma semana. $E$ possível que en saios posteriores venham demonstrar a possibilidade de terapêutica eficaz com 2 ou 3 doses adequadas de Ro 4-4393, administradas a intervalos mensais; não fica também afastada a hipótese de obtermos índices de cura apreciáveis após uma única dose, mais elevada, do quimioterápico em questão.

Concluindo, acreditamos ter demonstrado os seguintes fatos:

1 - O Ro 4-4393, administrado em doses de $20 \mathrm{mg} / \mathrm{kg}$ de pêso, a intervalos semanais, durante 4 semanas, é pelo menos tão eficaz quanto a aplicação tópica diária de tetraciclinas por períodos de 45 a 60 dias, nas condições do presente ensaio.

2 - O Ro 4-4393 representa recurso de grande utilidade nas campanhas de tratamento em massa do tracoma, graças à sua baixa toxicidade o facilidade de administração (via oral, intervalos semanais ou maiores).

3 - Não nos é possivel indicar o índice de cura máximo obtido com o Ro 4-4393 ou com os antibióticos, em vista do tempo ainda reduzido de contrôle.

4 - Os dados até agora obtidos sugerem a extensão do programa de estudos com o Ro 4-4393 na terapêutica do tracoma, utilizan. do posologia mais elevada e tempo menor de tratamento. 


\section{SUMMARY}

A new long-acting sulfamide, Ro 4-4393, has been assayed in the treatment of 350 trachomatous children from endemic areas, in comparison to the local use of antibiotic ointments. Different schemes of administration were alopted, posology ranging between 20 to $50 \mathrm{mg} / \mathrm{kg}$ body weight, in weekly, fortnightly and monthly intervals, and as a single dose. The results obtained with most of the therapeutic schedules were at least comparable to those given by topical antibiotics. The period of control is stili too short for definite conclusions, and the authors suggest the study of new groups treated with Ro 4-4393.

\section{BIBLIOGRAFIA}

1. BIETTI, G. \& LANZIERI, M.: - Rev. Int. Trach. 34: 270, 1957.

2. BIETTI, G. \& PANNARALE, M.: Rev. Int. Trach. 32; 354, 1955.

3. COMBATE ÀS ENDEMIAS RURAIS NO BRASIL - Relatórios dos grupos de trabalho, Rio - Gb., 1960.

4. FORSTER, W.G. \& Mc GIBONY, J.R. - Am. J. Ophth. 27: 1107, 1944.

5. GANDOLFI, A.: - Boll. Ocul. 43: 493, 1964.

6. I.N.E.Ru. - Sugestōes para ensaio terapêutico ao tracoma com a sulfa-ortodimetoxina (Ro 4-4393)
7. KAMIYA \& COLS. - Am. J. Ophth. 42: 269, 1956.

8. MILANC, C.. - Boll. Ocul. 43: 499, 1964.

9. MOUTINHO, J. - Rev. Int. Trach. 26: $223,1949$.

10. THYGESON, P.: - in Rivers, T. M. "Viral and Rickettsial Infections of Man”, Lippincott, 1952.

11. TITTARELI, R.: - Bull. Ocul. 43: $485,1964$. 


\section{CONGRESSO INTERNACIONAL DE} MEDICINA TROPICAL E MALÁRIA

Será realizado de 7 a 15 de setembro de 1968 em Teheran (Iran) o VIII Congresso Internacional de Medicina Tropical e Malária que contará com o seguinte comitê Executivo Internacional:

\section{Presidente:}

$$
\text { J. H. Salen (Iran) }
$$

Vice-Presidentes:

Divisão A: Medicina Tropical - B. G. Maegraith (U.K.)

Divisão B: Malária - A. Gabaldon (Venezuela)

Secretário:

Tesoureiro:

M. K. Afridi (Paquistão)

Membros:

$$
\text { J. C. Edozien (Nigéria) }
$$

J. Rodrigues da Silva (Brasil)

D. J. Davis (U.S.A.)

Secretário-Geral:

Enderêço:

$$
\text { M. H. Mofidi }
$$

P.O. Box 1310

Teheran - Iran

N.B. - Inscrições para temas livres até 31 de maio de 1968 .

\section{CCLEGIO INTERNACIONAL DE MEDICINA TROPICAL}

O Professo: T. A. Lambo (Ibadan) foi eleito Presidente do "International College of Tropical Medicine", e os Professôres R. N. Chaudhuri (Calcutá) e Harry Most (Nova Iorque) são vice-presidentes para 1967. Os outros membros do Conselho para 1967 são: Profs. R. H. Black (Sydney, Austrália), A. Bonebakker (Holanda), Ludolf Fischer (Tubingen), T. Harinasuta (Bangkok), B. H. Kean (Cornell), O. Kranendonk (Amsterdam), P. E. C. MansonBahr (Tulane), B. C. Maegraith (Liverpool), G. L. Monekosso (Lagos), M. Senkalé (Dakar), A. W. Woodruff (Londres), e Drs. A. Gabaldon (Caracas), J. W. Kibukamuscoke (Uganda), G. A. Myers (Provost I.C.T.M.), H.P. Ojiambo (Kenya) e M. V. Sheehan (Drogheda, Irlanda).

O Conselho decidiu promover o primeiro Congresso Internacional do Colégio no fim de 1967. Os detalhes do referido congres$\therefore$ serão publicados brevemente. 